\title{
UPAYA PENCEGAHAN ANEMIA PADA REMAJA PUTRI MELALUI KONSUMSI TABLET TAMBAH DARAH
}

\author{
Aida Fitria ${ }^{1}$, Siti Aisyah ${ }^{2}$, Jita Sari Tarigan Sibero ${ }^{3}$ \\ 123 Dosen Program Studi Kebidanan Institut Kesehatan Helvetia \\ Email: aidafitria@helvetia.ac.id, sitiaisyah@helvetia.ac.id, jitasari76@gmail.com
}

\begin{abstract}
ABSTRAK
Ketidakpatuhan remaja putri mengkonsumsi Tablet Tambah Darah (TTD) menjadi penghambat pencapaian program pemerintah pemberian TTD. Sumatera Utara menduduki peringkat ke 4 terendah untuk cakupan pemberian TTD sebesar 19,96\%, sedangkan target cakupan pemberian TTD sebesar 25\%. Pemerintah mengharapkan melalui program pemberian Tablet Tambah Darah (TTD) pada remaja putri dapat menekan angka remaja putri yang mengalami anemia. Bahkan, masih banyak remaja putri yang tidak patuh mengkonsumsi Tablet Tambah Darah (TTD) karena beberapa faktor, yaitu pengetahuan. Manfaat kegiatan pengabdian kepada masyarakat ini dapat memberikan informasi secara umum tentang anemia pada remaja putri serta pentingnya mengkonsumsi Tablet Tambah Darah guna pencegahan anemia pada remaja. Metode pelaksanaan kegiatan PKM ini menggunakan metode ceramah, tanya jawab dan pemberian tablet zat besi pada remaja yang dilaksanakan pada tanggal 25 Mei 2021 di Yayasan Perguruan Budi Agung Medan. Hasil kegiatan PKM berupa penyuluhan ini mendapatkan apresiasi yang kuat, peserta terlihat semangat mengikuti dan mendengarkan ceramah dan ada tanya jawab dari para peserta. Peserta penyuluhan juga antusias menerima Tablet Tambah Darah yang diberikan dan bersedia meminumnya di rumah. Oleh karena itu, diharapkan peserta dapat mengkonsumsi TTD yang diberikan secara berkelanjutan agar angka anemia pada remaja putri dapat menurun.
\end{abstract}

Kata Kunci: anemia, kepatuhan, konsumsi, tablet tambah darah

\begin{abstract}
The lack of compliance of teenage girls in taking iron tablets (TTD) is an obstacle to the achievement of the government's program of giving TTD. North Sumatra is ranked the 4th lowest for the coverage of administering TTD by 19.96\%, while the target for the coverage was 25\%.The government hopes that through the program of giving TTD to young women, it can reduce the number of young women who experience anemia. There are still many young women who do not comply with taking TTD due to several factors, namely knowledge. The benefits of this community service can provide general information about anemia in teenage girls and the importance of consuming TTD for the prevention of anemia. This service activity used the lecture method, question and answer and giving out iron tablets to teenagers and has been carried out on May 25, 2021 at the Budi Agung Education Foundation Medan. The results of the activity received a strong appreciation, the participants seemed enthusiastic to follow and listen to the lecture and there were questions and answers from the participants. They were also enthusiastic about receiving the TTD that were given and were willing to take them at home. It is suggested that participants can consume TTD continuously so that the anemia rate in young women can decrease.
\end{abstract}

Key Words : anemia, compliance with fe tablet consumption 


\section{PENDAHULUAN}

Masa remaja merupakan masa peralihan dari kanak-kanak menuju dewasa. Pada masa ini banyak terjadi perubahan pada diri seseorang, baik fisik maupun mental, sehingga harus diimbangi dengan kecukupan nutrisi. Namun, jika tidak menyebabkan terjadinya beberapa permasalahan gizi pada remaja, seperti obesitas, Kekurangan Energi Kronik (KEK), anemia dan lainnya (Mardalena, 2017). Untuk menjaga keseimbangan besi dalam tubuh, seorang wanita membutuhkan asupan zat besi lebih tinggi dibandingkan laki-laki. Wanita memiliki cadangan besi tubuh 25-30\%, sebanyak 20\% wanita memiliki cadangan besi tubuh sebesar 250-400 mg dan kurang dari 5\% memiliki cadangan besi tubuh lebih dari $400 \mathrm{mg}$. Maka, wanita sangat berisiko terkena defisiensi besi dan ADB (Anemia Defisiensi Besi) terlebih pada saat kehamilan (Supariasa, 2016).

Anemia zat besi merupakan masalah gizi mikro tersebesar di Indonesia, yang terjadi pada kelompok balita, anak sekolah, ibu hamil dan remaja (Maryam, 2016). Remaja perempuan dengan anemia berisiko melahirkan bayi BBLR $(<2500$ gram $)$, melahirkan bayi premature, infeksi neonatus dan kematian pada ibu dan bayi saat persalinan (Supariasa, 2016). Berbagai negara, termasuk Indonesia melaporkan angka prevalensi ADB (Anemia Defisiensi Besi) pada wanita hamil tetap tinggi meskipun bervariasi. Anemia Defisiensi Besi pada kehamilan di negara maju, yaitu rata-rata 18\%, sedangkan prevalensi rata-rata anemia pada wanita hamil di negara berkembang sekitar 63,5\%80\%. Anemia Defisiensi Besi akan menimbulkan intelligence quotient (IQ) rendah, penurunan kemampuan belajar dan penurunan angka pertumbuhan pada anak (Luh, 2015). Pemerintah mengharapkan melalui program pemberian Tablet Tambah Darah (TTD) untuk remaja putri dapat menekan angka remaja putri yang mengalami anemia. Faktor utama terlaksananya program tersebut, yaitu kepatuhan remaja putri mengkonsumsi TTD, yang dipengaruhi oleh pengetahuan sehingga sikap seseorang dapat berubah. Tingkat kepatuhan dimulai dengan mengindahkan setiap anjuran hingga mematuhi rencana. Namun, masih banyak remaja putri yang tidak patuh mengkonsumsi TTD karena beberapa faktor, yaitu pengetahuan, sikap, dukungan guru dan orang tua.

Berdasarkan data World Health Organization (WHO) tahun 2018, menyatakan bahwa sekitar 1,2 miliar orang atau 1 dari 6 populasi dunia adalah remaja berusia 10 hingga 19 
tahun lebih dari 1,1 juta remaja berusia 10-19 tahun meninggal tahun 2016. Anemia kekurangan zat besi adalah penyebab utama kedua remaja cacat dan meninggal tahun 2016. Suplemen zat besi dan asam folat adalah solusi yang dapat membantu meningkatkan kesehatan sebelum remaja menjadi orang tua (WHO, 2018).

Kemenkes RI (2018), menyebutkan bahwa pemberian TTD pada remaja putri di Indonesia tahun 2018 sebesar 48,52\% dan sudah memenuhi target renstra tahun 2018 yaitu $25 \%$. Provinsi dengan persentase tertinggi pemberian TTD pada remaja putri adalah Bali $(92,61 \%)$ dan persentase terendah Kalimantan Barat (9,62\%). Sebanyak tujuh provinsi belum memenuhi target renstra (25\%) tahun 2018, yaitu Kalimantan Barat (9,62\%), Kalimantan Tengah (12,58\%), Kalimantan Timur (17,01\%), Sumatera Utara (19,96\%), Maluku (22,23\%), Sumatera Selatan (23,56\%) dan Riau (23,86\%).

Berdasarkan data Riskesdas tahun 2018 terjadi peningkatan anemia pada ibu hamil sebesar 11,8\% dibandingkan tahun 2013, yaitu sebesar 37,1\% ibu hamil menderita anemia tahun 2013 dan tahun 2018 meningkat menjadi 48,9\%. Hal ini terjadi karena tingginya prevalensi anemia pada remaja putri yaitu sebesar $25 \%$ dan $17 \%$ pada WUS. Seorang remaja putri dikatakan patuh mengkonsumsi Tablet Tambah Darah (TTD) jika dalam satu tahun telah mengkonsumsi TTD sebanyak 52 tablet/butir. Cakupan konsumsi TTD pada remaja putri $<52$ butir $(96,8 \%)$ dan $\geq 52$ butir $(1,4 \%)$. Sedangkan remaja putri yang mendapatkan TTD sebanyak 76,2\% dan yang tidak mendapatkannya sebanyak 23,8\%, dari jumlah remaja putri yang mendapatkan TTD sebanyak $80,9 \%$ di sekolah dan 19,1\% tidak mendapatkan di sekolah (Riskesdas, 2018).

Lalu, dari Pemantauan Status Gizi yang dilakukan Seksi Kesga dan KIA bidang Kesehatan Masyarakat Dinkes Provinsi Sumatera Utara tahun 2018, diperoleh cakupan pemberian TTD untuk remaja putri sebesar 19,96\%. Tiga kabupaten dengan cakupan tertinggi, yaitu Pakpak Bharat (100\%), Karo (95,43\%) dan Samosir (95,34\%). Sedangkan 4 kabupaten dengan cakupan terendah, yaitu Toba Samosir (1,75\%), Padang Lawas Utara (6\%), Deli Serdang (8,24\%) dan Batu Bara (8,75\%), Dinkes Sumut (2018). 
Berdasarkan uraian di atas, pemerintah Indonesia berupaya mengatasi hal tersebut, seperti tertuang dalam Rencana Strategis Tahun 2015-2019 yang ditetapkan melalui Keputusan Menteri Kesehatan RI. No. HK.02.02/MENKES/52/2015, disebutkan bahwa salah satu acuan arah kebijakan Kementerian Kesehatan adalah penerapan pendekatan pelayanan kesehatan yang terintegrasi dan berkesinambungan (continium of care) untuk dapat melaksanakan pelayanan kesehatan yang holistik dan berkesinambungan terhadap seluruh tahapan siklus hidup manusia. Hal ini berarti pelayanan kesehatan dilakukan terhadap seluruh tahapan siklus hidup manusia (life cycle), sejak dalam kandungan sampai lahir menjadi bayi, tumbuh menjadi anak balita, anak usia sekolah, remaja, dewasa muda (usia produktif), dan lanjut usia (Kemkes, 2018).

Sesuai dengan Surat Edaran Direktur Jenderal Kesehatan Masyarakat Kementerian Kesehatan No. HK.03.03/V/0595/2016 tentang Pemberian TTD pada remaja putri dan wanita usia subur, bahwa pemberian TTD pada remaja putri dilakukan melalui UKS/M di institusi Pendidikan (SMP dan SMA atau sederajat) dengan menentukan hari minum TTD bersama. Dosis yang diberikan adalah satu tablet setiap minggu sepanjang tahun. Pemberian TTD pada remaja putri bertujuan memenuhi kebutuhan zat besi bagi remaja putri yang akan menjadi ibu di masa akan datang. Sehingga, cukupnya asupan zat besi sejak dini diarapkan dapat menurunkan angka kejadian anemia ibu hamil, pendarahan saat persalinan, BBLR dan balita pendek (Riskesdas, 2018).

Anemia pada remaja menjadi permasalahan yang diperhatikan pemerintah. Banyaknya remaja putri yang mengalami anemia pada masa remaja, karena ketidakpatuhannya mengkonsumsi TTD. Kepatuhan mengkonsumsi TTD berhubungan dengan beberapa faktor, seperti pengetahuan remaja putri tentang anemia dan manfaat dari TTD yang kurang, sehingga masih banyak remaja putri yang tidak patuh mengkonsumsi 1 tablet dalam 1 minggu secara continue selama 1 tahun.

Program pembagian Tablet Tambah Darah (TTD) merupakan program rutin dari pemerintah untuk penanggulangan dan pencegahan anemia pada remaja. Perguruan Budi Agung merupakan sekolah yang ada di Kota Medan. Survey awal yang dilakukan dengan mewawancarai 10 siswi diperoleh bahwa siswi tersebut mendapatkan tablet zat 
besi dari puskesmas sebanyak 1 kali. Dari 10 siswi mengatakan bahwa tidak mengetahui manfaat TTD dan bahaya anemia pada remaja, namun pernah mendengar tentang anemia tetapi tidak pernah meminum obat TTD tersebut. Berdasarkan pengamatan awal, terlihat banyak yang tidak mengkonsumsi pil tambah darah karena minimnya pengetahuan remaja putri tentang pentingnya mengkonsumsi TTD untuk mencegah anemia pada remaja. Adapun Pengabdian kepada Masyarakat ini berjudul "Upaya Pencegahan Anemia pada Remaja Putri melalui Konsumsi Tablet Tambah Darah".

\section{METODE PELAKSANAAN}

Kegiatan Pengabdian kepada Masyarakat ini dilaksanakan dengan melakukan penyuluhan kepada siswi di Yayasan Perguruan Budi Agung Medan pada tanggal 25 Mei 2021. Peserta kegiatan ini adalah siswi remaja putri yang ada di Yayasan Perguruan Budi Agung sejumlah 32 orang, yaitu remaja putri umur 12-15 sebanyak 21 orang dan remaja putri umur 16-18 sebanyak 11 orang. Kegiatan PKM ini dilakukan melalui beberapa tahapan, yaitu pada tahap pertama dilakukan kegiatan persiapan mulai dengan analisis situasi dan pemasalahan yang ada. Lalu, dilakukan proses pengurusan izin pelaksanaan kegiatan PKM di Yayasan Perguruan Budi Agung. Selanjutnya, kegiatan PKM dilakukan dengan melakukan penyuluhan. Selain itu, tim PKM melakukan evaluasi kegiatan berupa pre-post test untuk melihat ketercapaian kegiatan.

\section{HASIL DAN PEMBAHASAN}

Hasil kegiatan Pengabdian kepada Masyarakat yang telah dilaksanakan diperoleh bahwa peserta sangat antusias dalam menyimak materi yang disampaikan dalam penyuluhan. Selain itu, kegiatan PKM ini dibantu oleh 2 mahasiswa dan 2 dosen, sehingga kegiatan ini berdampak positif kepada peserta dan pelaksana kegiatan. Secara keseluruhan, kegiatan PKM berjalan dengan lancar dan memberi manfaat yang besar bagi peningkatan pengetahuan remaja putri di Yayasan Perguruan Budi Agung.

Karakteristik remaja putri di Yayasan Perguruan Budi Agung berdasarkan umur remaja putri terlihat bahwa frekuensi terbanyak remaja putri pada umur 12-15 tahun yang berjumlah 21 orang $(65,7 \%)$, diikuti dengan remaja putri berumur 16-18 tahun yang berjumlah 11 orang $(34,3 \%)$. Lalu, berdasarkan jenjang pendidikan yang ditempuh 
remaja putri terlihat bahwa terbanyak remaja putri sedang menempuh pendidikan SMP yang berjumlah 21 orang $(65,7 \%)$, diikuti dengan remaja putri pada jenjang pendidikan SMA yang berjumlah 11 orang $(34,3 \%)$.

Berikut dijabarkan frekuensi pengetahuan remaja putri sebelum dan setelah adanya penyuluhan tentang anemia dan tablet tambah darah, terlihat bahwa pengetahuan remaja putri sebelum diberikan materi penyuluhan, seluruh sejumlah 32 siswi (100\%) pengetahuan remaja putri masih kurang tentang pengetahuan anemia dan konsumsi TTD. Lalu, setelah diberikan materi penyuluhan tentang anemia dan konsumsi TTD terjadi peningkatan sejumlah 24 siswi (75\%) pengetahuan remaja putri menjadi baik, dan hanya 8 siswi (25\%) remaja putri dengan pengetahuan yan masi kurang tentang pengetahuan anemia dan konsumsi TTD. Oleh karena itu, rata-rata nilai pretest sebesar 42,81 dan rata-rata nilai postest sebesar 74,84, yang menunjukkan bahwa terdapat peningkatan pengetahuan remaja putri Yayasan Perguruan Budi Agung sebelum dan sesudah diberikan materi penyuluhan tentang anemia dan konsumsi TTD sebesar 32,03.

Adapun perbandingan pengetahuan remaja putri sebelum dan sesudah diberikan materi penyuluhan tentang anemia dan konsumsi TTD menunjukkan bahwa menggunakan Wilcoxon Signed Ranks Tset diketahui $p$ value pengetahuan 0,000, yang berarti terdapat perbedaan bermakna antara pengetahuan remaja putri saat pre test dan post test setelah diberikan materi penyuluhan tentang anemia dan konsumsi TTD. Sehingga, terdapat perbedaan terhadap pengetahuan remaja putri sebelum dan sesudah diberikan penyuluhan tentang anemia dan konsumsi TTD di Yayasan Perguruan Budi Agung.

Kegiatan PKM berupa penyuluhan tentang anemia dan konsumsi tablet tambah darah di Yayasan Perguruan Budi Agung dimulai dengan memberikan materi tentang anemia dan cara konsumsi TTD. Lalu, dilanjutkan dengan pembagian tablet tambah darah pada remaja putri, mengingat masih rendahnya cakupan konsumsi TTD pada remaja putri sebesar $<52$ butir yaitu $96,8 \%$ dan $\geq 52$ butir yaitu $1,4 \%$ (Riskesdas, 2018 ). 


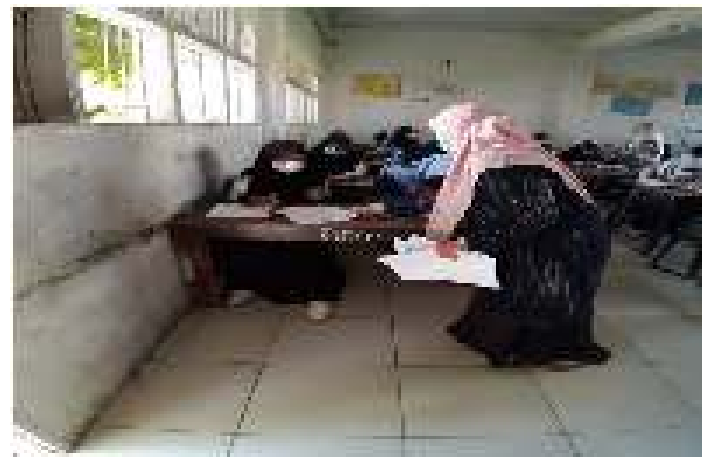

\section{Gambar 1. Pembagian Kuesioner Pretest pada Remaja}

Pemberian penyuluhan dilakukan karena melihat hasil penelitian yang dilakukan oleh Wisdyana Saridewi dan Kartika Dewi tahun 2019 yang menunjukkan bahwa adanya hubungan antara pengetahuan dengan kepatuhan dalam mengkonsumsi tablet tambah darah, dengan hasil uji statistik diperoleh hasil nilai $p=0,000$ (Saridewi, W., 2019). Pengetahuan merupakan hasil dari penginderaan terhadap objek melalui pengelihatan dan pendengaran. Selain itu, pengetahuan merupakan hal penting untuk terbentuknya tindakan seseorang, yang dipengaruhi oleh faktor internal yaitu pendidikan, pekerjaan, umur; dan faktor eksternal yaitu lingkungan dan sosial budaya. Pengetahuan akan mempengaruhi perilaku seseorang, sehingga perilaku yang didasari oleh pengetahuan lebih baik dari pada perilaku yang tidak didasari oleh pengetahuan (Wawan, A., 2015).

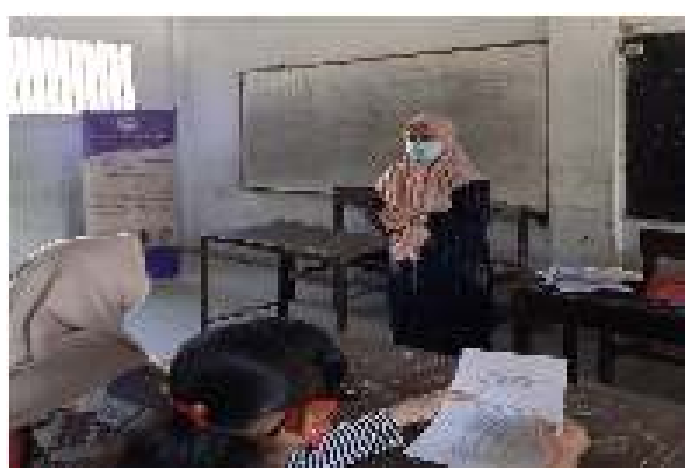

Gambar 2. Penyampaian Materi Penyuluhan

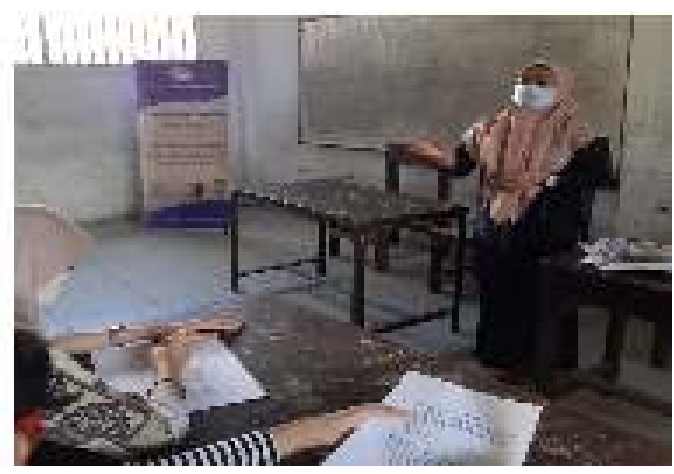

Gambar 3. Pembagian Kuesioner Posttest kepada Remaja Putri 


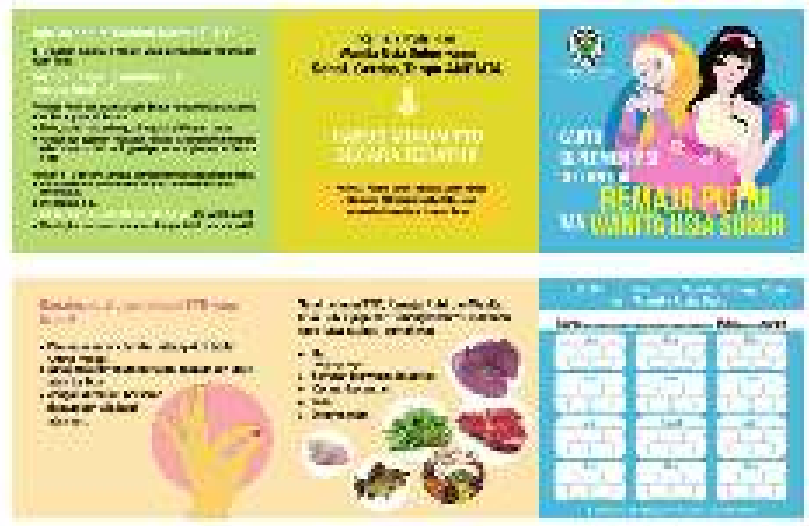

Gambar 4. Leaflet tentang Anemia dan TTD pada Remaja Putri

Pemberian leaflet tentang anemia dan TTD pada remaja diharapkan dapat memberikan informasi tambahan bagi para remaja dan membantu remaja untuk dapat membuat daftar ceklist jadwal minum tablet tambah darah yang ada di leaflet tersebut.

\section{KESIMPULAN DAN SARAN}

Pelaksanaan kegiatan Pengabdian kepada Masyarakat berupa penyuluhan tentang upaya pencegahan anemia pada remaja putri melalui konsumsi tablet tambah darah di Yayasan Perguruan Budi Agung Medan tahun 2021 telah berhasil dilakukan, peserta sangat antusias menyimak materi yang disampaikan. Keberhasilan kegiatan PKM ini ditunjukkan juga dengan hasil evaluasi peserta penyuluhan dengan nilai rata-rata pretest sebesar 42,81 menjadi rata-rata posttest sebesar 74,84.

Adapun saran yang dapat disampaikan setelah telaksananya kegiatan PKM ini adalah perlu adanya upaya keberlanjutan dari pihak sekolah untuk mengevaluasi keefektifan konsumsi tablet tambah darah melalui cek $\mathrm{Hb}$ para siswa. Selain itu, guru kelas juga diharapkan ikut berpartisipasi memotivasi siswa untuk teratur mengkonsumsi TTD. Adapun untuk remaja putri diharapkan dapat mengkonsumsi TTD yan diberikan secara berkelanjutan agar angka anemia pada remaja putri dapat menurun.

\section{UCAPAN TERIMA KASIH}

Tim pengabdi mendapatkan banyak bantuan dalam pelaksanaan kegiatan PKM ini, baik pada aspek moril maupun materil dari LPPM Institut Kesehatan Helvetia. Selain itu, tim pengabdi juga mengucapkan terima kasih kepada Pimpinan Yayasan Perguruan Budi 
Agung beserta para staf pengajar yang telah bekerjasama dengan baik sehingga kegiatan PKM ini dapat berjalan dengan lancar.

\section{REFERENSI}

Dinkes. 2018. Profil Kesehatan Sumatera Utara. Url: http://dinkes.sumutprov.go.id/v2/arsip-4-2018.html diakses pada 21 April 2021.

Kemenkes RI. 2018. Data dan Profil Kesehatan Indonesia 2018. Jakarta: Kemenkes.

Kemkes. 2018. Petunjuk Teknik Posyandu Remaja. Url: kesga.kemkes.go.id/images/pedoman/petunjukteknisposyanduremaja.pdf diakses pada 21 April 2021.

Luh, Seri A. 2015. Anemia Defisiensi Besi; Prahamil dan Hamil. Jakarta: EGC.

Mardalena, I. 2017. Dasar-dasar Ilmu Gizi dalam Keperawatan. Yogyakarta: Pustaka Baru Press.

Maryam, S. 2016. Gizi dalam Kesehatan Reproduksi. Jakarta: Salemba Medika.

Riskesdas. 2018. Url: https://www.litbang.kemkes.go.id/hasil-utama-riskesdas-2018/ diakses pada 21 April 2021.

Saridewi, W., Ekawati, K. 2019. Hubungan Pengetahuan dengan Kepatuhan dalam Mengkonsumsi Tablet Tambah Darah di SMAN 1 Ngamprah. Proceeding Publ Creat Res MLT DIV. 2019;1(1):87-92.

Supariasa, I., Dewa, NH. 2016. Ilmu Gizi Teori dan Aplikasi. Jakarta: EGC.

Wawan, A; Dewi, M. 2015. Teori dan Pengukuran, Sikap dan Perilaku Manusia. Yogyakarta: Nuha Medika.

WHO. 2018. Remaja; Resiko dan Solusi Kesehatan. Url: https://www.who.int/newsroom/fact-sheets/detail/adolescents-health-risks-and-solutions diakses pada 21 April 2021.

Yohanes, S. 2017. Sehat dan Cerdas untuk Remaja. Yogyakarta: Publishing. 